\title{
Equity, diversity and working hours: Challenges and solutions
}

This special issue is devoted to a refereed and edited selection of papers presented at the XVIth International Symposium on Night and Shiftwork held in Santos, Brazil, in November 2003. The journal Chronobiology International has also an issue (volume 21, n. 6, 2004) dedicated to that Symposium. Held every two years, these symposia are organised under the auspices of the Working Time Society and the Scientific Committee on Shiftwork of the International Commission on Occupational Health (http://time.iguw.tuwien.ac.at/index.htm). For many years they have been the key international gatherings of researchers concerned with the relationships between working hours, human biology and behaviour, health and safety. They are not only unrivalled opportunities to discuss developments in working time research but are also important social gatherings of a close-knit, but growing, scholarly community. The choice of venue, which broke from the tradition of offering the symposia in isolated locations, offered an ideal combination of an enclosed and self-sufficient conference centre, according to the attendees' opinion.

The theme of the Santos symposium was "Equity and working time: A challenge to be achieved". Increasing workplace diversity and the growing recognition of the need to manage it more equitably are undoubtedly issues with great contemporary resonance. At least two other recent international developments, the growth of "flexible work" and the ageing of the workforce in many countries, also present significant new challenges and opportunities for working hours research. Although workforce ageing has attracted substantial public and political attention in recent years (Taylor et al, 2004), little systematic consideration has been given to the occupational health implications and working hours researchers, who for some time have had an interest in older workers, are in a position to provide some leadership in this regard. Various rapidly expanding forms of precarious or contingent work, particularly short-term temporary and casual work, are often promoted as "flexible" and "family-friendly". However, this flexibility is most often organisational rather than individual, and frequently leads to more diverse, and often irregular, shift systems (Golden, 2001) and the growth of extreme work schedules that combine shiftwork with very long hours (ACIRRT, 1999). These undesirable working hours appear to be one factor contributing to the variety of negative effects of health and safety associated with precarious employment (Quinlan \& Bohle, 2003). These developments are currently stimulating a shift away from the traditional focus of shiftwork research on full-time workers in ongoing employment toward a greater concern with workers in various forms of flexible employment.

The papers published in this issue pick up the symposium theme of equity and diversity, the ageing of the workforce and workplace flexibility. Friedhelm Nachreiner examines the topical, though still under-researched, issue of accommodating diversity in the design of work schedules. His provocative overview examines equity in relation to aspects of diversity already given some attention in working hours research (gender, marital status, social support, age and personality) and extends to others that have received somewhat less recognition (cultural values, socioeconomic differences). Several papers then examine the impact of variations in working hours on variables of long standing in shiftwork research: sleep, subjective health and wellbeing, and satisfaction. They describe negative effects of night work on specific aspects of quality of life (Kaliterna Lipovcan, Prizmic Larsen \& Zganec); the negative impact of high variability in working hours, especially company-controlled 
variability, on health and social lives (Janssen \& Nachreiner); the disadvantage of casual (temporary) hotel workers in relation to unpredictable hours over which they had little control, work-life conflict and health (Bohle, Quinlan, Kennedy \& Williamson), national differences in negative impact of night shift on perceptions of physical and mental tiredness (Tepas et al); and impact of the timing and duration of night-time naps on the sleep and performance of night workers (Takeyama et al). In the following paper, Radoševic-Vidacek and Košcec report an interesting and unusual study examining the impact of parents' work schedules on adolescents' sleep. It is unusual because the students also attend school on weekly rotating morning and afternoon shifts. The results indicate that adolescents with parents in shiftwork are disadvantaged in terms of waking times, sleep duration and bedtime irregularity, particularly when they themselves were on the "morning shift".

Four papers then deal with aspects of what can be broadly labelled "work schedule design". Jeppesen and colleagues examine the implications for shiftworkers applying different number of teams in the shiftwork organization. They worked in different firms, sharing the same product organization and a common corporate culture, in the same multinational company. Gärtner manuscript evaluates conflicts between employees' preferences and ergonomic recommendations in shift scheduling. He concluded that achieving consent does not ensure ergonomically sound schedules. And procedures of risk assessment seem to be promising, but still is a difficult approach. Carsten Schomann and his colleagues describe the development of a computer programme for the design and evaluation of shift schedules (BASS 4). The new aspects implemented in this programme included the concept of criterion functions, resulting on the integration of workload-related aspects. Kazutaka Kogi examines industry-based guidelines on night and shift work and enterprise-level intervention projects to design a new checklist to facilitate the shiftwork interventions.

The concluding paper, by the President of the Working Time Society, Prof. Giovanni Costa, presents a reflection on the approaches and strategies to promote and to protect the shiftworkers' health. According to Costa, a more effective and profitable adoption of preventive and compensative measures can be achieved through a systemic approach, taking into account the many domains involved on this issue.

As always, this volume reflects the labour of many people. The editors wish to extend their sincerest thanks to the many referees who contributed so generously of time and expertise, frequently offering unusually detailed and insightful feedback to authors. We also wish to express our appreciation to Dr. Maria Teresinha Dias de Andrade, Executive Editor of the Journal of Public Health (Revista de Saúde Pública) for providing the opportunity to publish this collection in and for supporting us so fully through the editorial process. Finally, we wish to thank the authors for their stimulating contributions to research and debate on working hours and shiftwork.

Philip Bohle

Frida Marina Fischer

Lúcia Rotenberg

Cláudia Roberta de Castro Moreno

Editors

\section{REFEREN CES}

Australian Centre for Industrial Relations Research and Teaching [ACIRRT]. Australia at work: just managing? Sydney: Prentice Hall; 1999.

Golden L. Flexible work schedules: what are we trading off to get them? Mon Labor Rev 2001;3:50-67.

Quinlan M, Bohle P. Contingent work and occupational safety. In: Barling J, Frone MR, editors. The psychology of workplace safety. Washington (DC): APA Books; 2003. p. 81-106.

Taylor P, Masato O, Rolland L. Work and retirement in the Asia-O ceania region: perspectives on longer employment and flexible retirement. Geriatr Gerontol Int 2004;4:S190-3. 